\title{
Encouraging reflective practice in periods of professional workplace experience: the development of a conceptual model.
}

\author{
Dr Andrew Roberts \\ Welsh School of Architecture, Cardiff University \\ Higher Education Academy, Centre for Education in the Built Environment \\ Bute Building \\ King Edward VII Avenue \\ Cardiff \\ CF10 3NB \\ Email: RobertsAS@cf.ac.uk
}

Tel: 02920874602

\section{Summary}

It is common in many professional subject areas for students to undertake periods of work-based experience as part of their studies. Research suggests that by reflecting on their experience, student learning can be enhanced. As a result it is common for students to produce reflective diaries, journals, logs or eportfolios during their placements. The paper reviews literature on reflective practice and relates it to the findings of a number of small scale studies investigating students' perceptions of recording and reflecting in the built environment professions, principally architecture and construction management. The findings suggest that the levels of reflection that students achieve are likely to be influenced by their individual propensity and willingness to reflect, the focus of reflection that students perceive they need to adopt, and the structure and support students are provided with to help them reflect. The paper concludes by proposing a hypothetical model that relates these issues.

\section{Brief Biography}

Dr Andrew Roberts is a lecturer in the Welsh School of Architecture, Cardiff University. He is also Deputy Director for Architecture and Landscape at the Higher Education Academy, Subject Centre for Education in the Built Environment. His research interests are in the area of Architectural Education, particularly in the learning that occurs whilst students are undertaking work placements. His Ph.D was on the subject of cognitive styles and architectural education. 


\title{
Encouraging reflective practice in periods of professional workplace experience: the development of a conceptual model.
}

\begin{abstract}
It is common in many professional subject areas for students to undertake periods of work-based experience as part of their studies. Research suggests that by reflecting on their experience, student learning can be enhanced. As a result it is common for students to produce reflective diaries, journals, logs or eportfolios during their placements. The paper reviews literature on reflective practice and relates it to the findings of a number of small scale studies investigating students' perceptions of recording and reflecting in the built environment professions, principally architecture and construction management. The findings suggest that the levels of reflection that students achieve are likely to be influenced by their individual propensity and willingness to reflect, the focus of reflection that students perceive they need to adopt, and the structure and support students are provided with to help them reflect. The paper concludes by proposing a hypothetical model that relates these issues.
\end{abstract}

Keywords: work based learning, reflective practice, e-portfolios

There is evidence to suggest that certain aspects of the development of professionals are best learned in the workplace rather than through more formal academic situations (Eraut, Alderton, Cole, \& Senker, 2000; Little, 2004). For this reason, many professional subject areas require students to undertake periods of work-based experience as part of their studies. This learning can be enhanced through the use of techniques that encourage reflection (Blackwell, Bowes, Harvey, Hesketh, \& Knight, 2001). It is common, in such circumstances, for students to produce reflective diaries, journals, logs or e-portfolios in order to reflect upon their experience.

Much has been written on the subject of reflective practice in the fields of teacher education and the health sciences and whilst the concept of reflective practice is discussed within built environment departments (particularly in architecture), there appears to be little subject-specific research into its pedagogic benefits. This paper summarises a number of small-scale investigations with students of the built environment, that generally support the espoused wisdom on reflective practice found in other disciplines. As a result of these studies, it is possible to generate a 
tentative model that would help educators and researchers understand how the levels of reflection undertaken by students can be enhanced.

In the UK a number of professional institutions provide systems that encourage students to record and reflect upon their workplace experience. The Royal Institute of British Architects has created an online Professional Education and Development Record (PEDR) (RIBA, 2008). In this document, which is updated quarterly, students briefly describe the projects they are working on, provide a free-write evaluation of their recent experience and set goals for future development. Particular emphasis is placed on the number of hours spent on different activities (for instance meeting with clients, preparing drawings and documentation, talking to building contractors etc...). The PEDR is typically completed during the 'year out' placement and also during a compulsory period of pre-registration experience. Graduates wishing to register as architects are required to submit their PEDR records together with a $\mathrm{CV}$, a reflective professional experience evaluation and an evaluative case study related to a project they have worked on in their office. Students in other built environment subjects can use the web-based RAPID system (Maddocks \& Wright, 2004). This system provides a structured framework to enable students to identify skills and competencies that they need to develop. The students can self-assess their current skills, set goals for further development and present evidence of how this has been achieved. This can then be used to showcase a student's experience to a future employer. Unlike the architecture system, there is no professional compulsion to use the RAPID system.

\section{Benefits of Reflective Practice}

A wide body of literature has been developed on the subject of reflective practice, with writers arguing that reflection facilitates the linking of theory and practice, and encourages critical evaluation (Bain, Ballantyne, Packer, \& Mills, 1999; Calderhead, 1988). Reflection also provides the link between an experience and learning from 
that experience (Blackwell et al., 2001), providing meaning to something that is often personal and subjective (Platzer, Snelling, \& Blake, 1997, p. 104). Schön (1983) argues that reflective practice is a key attribute of being a professional. There appears however to be rather less literature providing evidence to show that encouraging students to reflect improves their resultant actions. To some extent this remains an assumption, albeit one that us underpinned by a number of seminal pieces of literature.

Whilst the concept of reflective thinking is generally first attributed to Dewey (1933), it is Schön (1983) who develops the link between reflection and professional thinking, suggesting that this is how professionals deal with complex and often ambiguous problems. Rather than attempt to apply some readily available theory or procedure to a situation, he argues that professionals use more intuitive processes which he refers to as 'Reflection on Action', and 'Reflection in Action'. Both suggest that reflection is closely bound with action, but the latter suggests reflecting on something whilst doing it, rather than at some subsequent period in time. Hatton and Smith (1995) suggest that it is this Reflection in Action that is the ultimate goal for the development of reflective capacity in students (p46).

For Kolb (1984), reflection represents a key element of his development of Lewin's experiential learning cycle. He suggests that students reflect upon a concrete experience that they have undertaken. They then use this reflection to draw conclusions and further conceptualise what they have experienced, which they can feed into further concrete experience though experimentation. Again reflection is closely bound up with action, and Kolb claims that the pursuit of this cycle leads to new learning. Moon (1999) provides a more sophisticated cyclical model based around how meaningful learning is assimilated and subsequently accommodated into what Ausubel and Robinson refer to as the cognitive structure. This is the network of 'facts, concepts, propositions, theories and raw perceptual data that the learner has 
available to him at any point in time' (Ausubel \& Robinson, 1969; cited in Moon, 1999, p. 108). As the cognitive structure accommodates new material, students are able to progress to further levels of learning and cognitive challenge. Moon argues that by reflecting, students are able to 'upgrade' their learning to even higher levels after the original time of learning (Moon, 1999, p. 147).

A number of approaches have been taken to categorise the different types and levels of reflection that students may demonstrate. Some have developed a series hierarchical classifications outlining the levels of cognitive sophistication achieved by the students (Hatton \& Smith, 1995; Van-Manen, 1977). Hatton and Smith's taxonomy ranges from non-reflective Descriptive Writing, through basic Descriptive Reflection, a more analytical Dialogic Reflection and finally to Critical Reflection. Others have attempted to distinguish between the cognitive level of reflection and the subject or focus of reflection in their classifications (Bain et al., 1999; LaBoskey, 1993; Valli, 1993). Similarly Kember et al (1999) have developed a scale, derived from the work of Mezirow on transformative learning. The scale represents a typology by which passages of reflective writing can be categorised. It differentiates between non-reflective activities, reflection on process, reflection on content and a high level premise reflection, later referred to as critical reflection (Kember et al., 2000), which can lead to a transformation in perspective.

In order to gain an understanding of the benefits of reflection for built environment students, a series of semi-structured interviews were carried out with 21 Architecture and Construction Management students from three UK universities undertaking periods of work-based experience, which included an assessed requirement to record and reflect upon their professional experience. The students were using one of three recording tools, namely the RIBA's PEDR, the RAPID system and an eportfolio component of the Blackboard virtual learning environment. About half of the students were undertaking, or had just returned from a period in practice; the 
remainder were recent graduates, working in practice and studying for their final professional examinations. Interview questions focussed upon three principal themes: the students' perceptions of the benefits of recording and reflecting on their experiences; the processes by which they carried out their recording and reflection; and the factors, that the students felt influenced the eventual outcomes. These factors might have been internal (i.e related to the student) or external (i.e related to the structures and frameworks provided by the recording tool.)

The interviews were carried by a research assistant mainly on a face to face basis, although some were conducted over the telephone. The interviews were tape recorded, and subsequently transcribed. Passages from the transcriptions were classified and categorised using NVIVA software. Classification was carried out independently, and iteratively by the author and the research assistant. The findings are only briefly summarised here, but full details are provided by Roberts \& Mizban (2008).

The interview data suggests that many students perceive that recording and reflecting on their achievements leads to beneficial outcomes; many of which concur with the literature on reflective practice. A key benefit is students start to recognise the extent of their achievement in terms of what they have learned, and the quantity, variety and significance of what they have done. Often students express surprise over the extent of their achievement. This can result in an improvement in students' confidence. Many would keep notes in a separate hand written diary, and then compile these into the formal system at longer intervals. This provided them with an opportunity to review their progress over an extended period of time, to recognise the relative significance of the various activities they had been involved in. The process of translation between paper, and electronic system, provided a useful opportunity for further reflection. This concurs with the findings of Smith and Tillema (2003) who 
argue that it is the process of constructing the portfolio, rather than the final product itself, is where the actual learning takes place.

The interview data also suggests that recording achievement provides an opportunity for students to contextualise and make sense of their role, and the work that they are undertaking. It helped to clarify matters which may initially appear confusing to the student. A further benefit, highlighted by many students, was that they were able to identify those areas where they might personally improve, highlighting strengths, weaknesses and identifying gaps for further development.

The benefits of reflecting on experience demonstrated through the interviews were supported in an evaluation questionnaire, issued to 51 architecture students recording and reflecting on a year in professional practice. Approximately threequarters of the students reported positive outcomes, particularly in terms of recognising how much had been learned during their workplace experience, and in terms of their portfolios helping them to make sense of what they had done in the office. Nevertheless, concern must be given towards the quarter who did not recognise any benefit. These often saw it as a necessary, but unhelpful chore, arguing that learning and development occurred through experience and face to face discussion, rather than through reflection.

\section{Individual Pre-disposition Towards Reflection}

The interview data referred to above suggested that students had varying motivations and attitudes towards reflection. The data suggested that those students who were more inclined towards reflecting described the more positive benefits. This was supported by a small scale study investigating students' perceptions of using learning journals in architecture (Roberts \& Yoell, Awaiting Publication). In this research, semi-structured interviews were carried out with nine Architecture students who had completed a compulsory learning journal during the previous year. Tentitive findings suggested that students could be classified into three categories. 'Natural 
Reflectors', were pre-disposed to reflecting, and found the process of writing their learning journal beneficial. These students did not need to be convinced by staff members that there were benefits to keeping a learning journal. They would generally use their learning journals thoroughout the year to help them with their studies. By contrast 'Disengaged' students, struggled to see any personal benefit of keeping a learning journal, but completed it in order to meet an assessment task. They tended to be critical of the requirement to keep a learning journal and appeared to be overly concerned with the presentation of their work, rather than the content. They were typically concerned with how much work they would be required to undertake in order to pass, and generally only updated their journals shortly prior to a tutorial. Their outputs tended to lack personal commentary or critique. One further group, who were initially sceptical about writing a learning journal, recognised after completing it that it might have been of benefit. These were labelled as 'Converts'. They reported that they had subsequently developed reflective habits and had developed critical and reflective awareness.

This suggestion that not all students may be pre-disposed to reflective practice concurs with Labosey's work with teachers undergoing their initial periods of teaching practice (LaBoskey, 1993, 1994). Using an open-ended questionnaire, Laboskey attempted to measure student tendencies towards what she refers to as "spontaneous reflectivity...situations where an individual displays reflective thinking, or not, in response to an indirect question or circumstance" (LaBoskey, 1993, p. 29). This led to the recognition of two distinct student types: 'Alert Novices', who are willing to reflect, and learn from their reflection, and 'Common Sense Thinkers', who base actions on what they know already from prior experience (in the teacher education case that being from being a school pupil) and thus they feel there is little more to learn. Laboskey's research suggested that the level of reflection demonstrated by Alert Novices in their reflective journals was much higher than for 
the Common Sense Thinkers. She recognised that additional work was required to bring the Common Sense Thinkers to the level of the Alert Novices.

Learning style theories highlight an individual's preference for a particular way of thinking and learning. That preference can be located somewhere on a continuum between the two extremes. Kolb (1984) for example suggests a continuum between Reflection and Action. Reflective learners may concentrate on the personal meaning of what they have learned, whilst active learners prefer testing their knowledge in practice. Kagan and colleagues suggest a dimension between Reflection and Impulsivity (Kagan, Rosman, Day, Albert, \& Phillips, 1964). This is typically measured on an individual's response speed and accuracy when shown a set of similar or dissimilar figures. If response time is slow but accurate, it is assumed that the individual is reflective. Whether this represents the same concept of reflection described thus far is uncertain.

A key aspect of learning style models is that neither end of the continuum is considered to be 'better' than the other, but rather is a relative preference. Knowledge of individual's styles can be used to tailor learning tasks and approaches. Furthermore someone who is given a label at the opposite end of the continuum from reflection is not necessarily unreflective, but would have a relative preference towards the other learning style (Riding \& Rayner, 1998).

These arguments suggest that students will bring to a learning situation a certain set of pre-conceived ideas, values, attitudes and abilities which are likely to impact on the extent to which they reflect on their experiences. Some of these may be as a result of a student's prior experience, whilst others may be hard-coded into an individual's personality. What remains unclear is the extent to which an individual's propensity to reflect can be developed, and whether reflection can be taught, with no clear viewpoint amongst contributing scholars. Nevertheless, it is possible that by 
providing appropriate scaffolding, then those less inclined to 'spontaneously' reflect, may achieve some of the outcomes experienced by more inclined reflectors.

\section{Context for reflection}

Although a student's propensity to reflect may affect the level of reflection achieved, the method by which data is recorded (learning journal, e-portfolio, diary etc...) may have a significant impact on what is written. More specifically any structure or guidance on what to write may also affect the nature of the students' reflection. In the research carried out on 21 built environment students referred to earlier, one recording tool, the RIBA's PEDR, was perceived by the students primarily as a means to demonstrate that sufficient work had been done to qualify as an architect, rather than as being of benefit to the student in terms of their learning. The tool places a heavy emphasis on recording the number of hours spent undertaking particular tasks. There is some provision for students to reflect on their experience, but little guidance is provided. The students therefore perceive the tool as being concerned with amassing information, rather than engaging in some form of critical evaluation.

This concurs with research carried out by Bain et al (1999) which suggest four different foci of reflection which might be generalised to focussing on the activity being undertaken, the self, professional issues and the context in which the activity takes place. Other research suggests that different frameworks for recording and reflection lead to different types of output and different types of reflection. Typical outputs might be a demonstration of an individual's credentials or competencies in order to obtain professional accreditation or employment or something more reflective that may have a benefit towards a student's learning (Barrett, 2007; Zeichner \& Wray, 2001). Orland-Barak (2005) re-words this distinction as between a product and process portfolio, a product portfolio being a documentation of evidence to demonstrate achievement, with a process portfolio being about the documentation 
of learning processes. Smith and Tillema (2003) make a further distinction between whether completing the portfolio is a mandatory requirement or is some thing that can be completed voluntarily. They identify 4 types of portfolio that result from these distinctions:

A dossier portfolio, provides a mandatory record of achievement, or evidence in order to demonstrate particular professional standards.

A training portfolio is a mandatory collection of evidence collected during a course of study to demonstrate the knowledge, skills and competences gained.

A reflective portfolio is a personally constructed portfolio demonstrating growth and development. The emphasis is on self appraisal, and the commentary and reflection on any evidence is considered to be the focus.

A personal development portfolio is a reflective account of development over a period of time, and is used for refining and structuring one's future development.

[Insert figure 1 here]

Whilst these are useful distinctions, and there is some evidence from the collected data that student's portfolios could map onto these categories, Smith and Tillema imply that mandatory portfolios can never be reflective. This is problematic given that the interview data suggested that students were unlikely to engage fully unless the exercise was mandatory. Furthermore, their model also pays little attention to the nature of the student, and their willingness to reflect in the way that has been previously discussed.

The students interviewed appeared to value being provided with some form of structure or framework to help them reflect and this was provided by the Blackboard E-Portfolio and the RAPID system. It was felt that this lead to deeper reflection than might be possible in un-structured circumstances, something also evident in the student's reflective writing. Nevertheless, there were concerns that the structure 
could become too rigid and students would be forced to distort the reality of their experience to meet the recording format. Other students claimed that they had felt obliged to write something, when there was really very little to say (perhaps suggesting that they needed more help in knowing what to write or how to be reflective). Other students felt that because the work was assessed, they could not be as free with their reflection as they otherwise might.

This finding is supported by other studies that suggest that some form of intervention is required to support a level of reflection that goes beyond the basic level of description (Bain et al., 1999; LaBoskey, 1993; Samuels \& Betts, 2007; Karen Smith, Clegg, Lawrence, \& Todd, 2007). Many students will struggle to reflect if they are simply asked to complete a piece of reflective writing without any further guidance or structure (Bean \& Stevens, 2002; Cox, 2005; Moon, 1999; Walker, 1985). It may also be necessary for different strategies to be adopted by those new to reflection and those who need to take reflection to higher levels (LaBoskey, 1993; Samuels \& Betts, 2007). Bean and Stevens (2002) suggest a need to provide 'scaffolding' in terms of both cognitive and emotional support. This might include the selection of activities to undertake, providing hints and prompts to encourage deeper reflection and providing feedback on their reflection to ensure motivation is maintained. Samuels and Betts (2007) argue that engaging in dialogue has the potential to promote deeper levels of reflection, which might take place orally or in the form of feedback on journal writing. Many authors have produced models of how prompts for reflection might be developed (Boud, Keogh, \& Walker, 1985; Cox, 2005; Johns, 1994) Critical Incident Analysis can provide a further framework for reflection by which students focus upon a significant moment for their reflection (Griffin, 2003; Tripp, 1993)

In addition to providing guidance and prompts, intervention by other individuals may be necessary to steer the direction of thought, or to ensure that misconceptions do not occur. Johns (1994) argues that reflection should always be coached or 
supervised. Similarly, Boud et al (1985) suggest that some form of cathartic discussion is needed in order to deal with negative thoughts that arise as a result of reflection. Cox (2005) highlights the importance of one to one debriefing, which can be used to draw out reflections from a student. Bain et al (2002) argue that feedback to students on their reflective writing processes is a particularly important element of encouraging high levels of reflection.

\section{Development of a Conceptual Model}

The findings of the research outlined above suggest three principal dimensions that could influence the type and level of reflection undertaken by students. Firstly there was the student's propensity to reflect: whether they are naturally inclined to spontaneously reflect even when not required; whether they will reflect when provided with support and guidance, or whether they struggle to engage with the whole concept of reflection. Secondly there was the student's perceptions of the required purpose or focus of reflection: whether they perceive the purpose of the exercise as highlighting their reflections on a process, or focussing on the product of their actions. Thirdly there was the degree to which support, guidance, frameworks and structure are provided.

From this, it is possible to propose a hypothetical model that connects the perceived purpose of reflection, and a student's propensity to reflect with the level of reflection typically achieved (Figure 2). The model is based initially on that proposed by Smith and Tillema (2003) in that it suggests 4 possible types of portfolio output. Rather than focussing whether portfolios are mandatory, it references a students propensity to reflect.

\section{[Insert Figure 2 here]}

The vertical axis represents the focus of reflection that the students perceive they are expected to adopt. A product focus, concentrates on what the students have done, a process focus concentrates on how they have done whatever they have done. This 
focus may be an implication of the nature of the recording tool, the instructions given to the student, or the student's perception of what is required of them.

The horizontal axis represents a continuum between those students who are naturally inclined to reflect (Reflectors), and those who might be more inclined to record their experiences in a matter of fact manner (Recorders).

Those who fall into the category of Recorders, whose perceived goal is to collect evidence of their experience, are likely to generate a dossier, which might be characterised by lists of activities undertaken, together with a number of pieces of evidence to show what they have done. There is likely to be little critical commentary explaining the evidence and linking it to their own personal development. Those who fall into the category of reflectors, who are asked to collect evidence, are more likely to annotate their portfolio, perhaps, providing un-solicited reflective comment on their achievements.

Reflectors who are encouraged to produce a portfolio focussed on learning processes are more likely to be critical and reflective. They are likely to produce work that shows evidence that they are aware of their own self-development, perhaps even experiencing a transformative experience in learning (Mezirow, 1990). By contrast when recorders are asked to produce a portfolio focussed on learning processes they may attempt to answer questions or prompts provided to them, but this may become a 'tick-box' exercise, trying to answer questions in a way that they believe will satisfy the assessor rather than engaging in a deep, personal reflection. If no prompts are provided, then they may struggle to know what to write and the outcome may be a description of what they have done with little critical evaluation. In this case the student may provide excessive attention towards the presentation of the work, rather than the content.

A model of this kind implies that recorders are unlikely to achieve particularly high levels of reflection. Nevertheless as this paper has suggested, the provision of 
appropriate structure and support which may include the provision of guidance and feedback, can help students produce reflective outputs, even if they are not naturally inclined to do so. In the case of this model, when support of this type is provided the boundary between reflective and non-reflective thinking may shift towards the top right in the direction of the arrow shown if figure 2. Nevertheless, questions still exist about those students who might be at the extreme end of the recorder-reflector continuum, who may always struggle to produce highly reflective work.

This would be of specific relevance within the subject of architecture where all students are required to undertake at least 24 months of monitored and recorded experience. At present the RIBA's PEDR encourages a product focus in the students' reflections and as a result some outputs might be described as 'dossiers'. The encouragement of a process focus, and some additional guidance from staff, could lead to the demonstration of a higher level of reflection, perhaps at structured evaluation, or even critical reflection level.

This model remains speculative, being based on a literature review and some limited empirical data. Further research is required to test the model which may investigate number of key facets. Firstly there is a need for further exploration of the continuum that has provisionally been identified as Reflector-Recorder. Whilst it does appear that some students may be more spontaneously reflective than others, what remains less clear is the nature of those students who appear at the non-reflective end of the continuum. LaBoskey (1994) describes these individuals as Common Sense Thinkers, who tend base their judgements on personal experience, and lack an awareness that they need to learn beyond this. This may be more appropriate to subjects such as teacher education, where students will have encountered personal experiences of being a school pupil. In subjects such as architecture, where students often undertake tasks that are relatively unfamiliar, they are less likely to demonstrate a 'Common Sense' viewpoint. 
An alternative view as to the nature of the 'Recorder' end of the continuum was highlighted in the study by Roberts \& Findlay (Awaiting Publication). Here the nonreflective individuals were described as 'disengaged', suggesting that they couldn't see the point in reflection. Perhaps these students don't have a natural faculty to reflect, or some external factor is preventing them from positively engaging in reflection, for instance a lack of confidence, or unwillingness to share inner thoughts. Perhaps the students are not aware of the potential for reflection.

Any further research into a student's propensity (or willingness) to reflect is likely to require some measurement. The authors of learning style models often produce tests which can quickly assess an individual's style, and a number of these claim to measure a student's preference towards reflection. Nevertheless, there are concerns about the validity and reliability of many of these tests (Coffield, 2004).

LaBoskey (1994) developed an open-ended questionnaire designed to measure 'spontaneous reflectivity' amongst trainee teachers. There are no external studies of its validity and reliability of this instrument available, but given that its results are derived from the interpretation of a piece of students writing, it shows a reasonable degree of face validity. Nevertheless it is time consuming to analyse, and would need considerable modification to be useable in disciplines outside the area of teacher education. An open ended instrument could also be used to identify the barriers and impediments that make reflection more difficult for certain individuals.

Once a better understanding of the individual nature of students has been reached, it would be possible to relate individual student preferences to the levels of reflection actually demonstrated by students in their work. To what extent do students who are reflectively inclined, demonstrate high levels of reflection in their reflective writing? In order to monitor the effect of the provision of structure or scaffolding it may be necessary to compare the students' performance in two tasks, one where guidance and structure is provided and another where students are asked to complete an 
open-ended piece of writing. Similarly it would be necessary to conduct a comparison of students' performance on two tasks which imply a different focus of reflection, whether on product or process. This would give an indication of how focus of reflection might impact on the outcomes achieved. Levels of reflection might best be measured using one of the scales highlighted earlier in this paper.

The paper has reviewed a number of studies of reflective practice mainly in the area of initial teacher training. It has attempted to relate these to studies carried out in Built-Environment courses. This has lead to the development of a tentative model of reflective practice that builds on previous models, but also incorporates the individual's propensity (or willingness) to engage in reflective practice. Given further development, such a model would have specific benefits for those responsible for overseeing placements in a range of professional subjects. With knowledge of students' propensities to reflect and the appropriate focus of reflection, tutors can tailor activities to maximise the students' reflection.

\section{References}

Ausubel, D. P., \& Robinson, F. G. (1969). School Learning : An Introduction to educational psychology: Holt, Rinehart and Winston.

Bain, J. D., Ballantyne, R., Packer, J., \& Mills, C. (1999). Using Journal Writing to Enhance Student Teachers' Reflectivity During Field Experience Placements. Teachers and Teaching, 5(1), 51 - 73.

Bain, J. D., Mills, C., Ballantyne, R., \& Packer, J. (2002). Developing Reflection on Practice Through Journal Writing: impacts of variations in the focus and level of feedback. Teachers and Teaching, 8(2), 171 - 196.

Barrett, H., C. (2007). Researching Electronic Portfolios and Learner Engagement: The REFLECT Initiative. Journal of Adolescent \& Adult Literacy, 50(6), 436449.

Bean, T. W., \& Stevens, L. P. (2002). Scaffolding Reflection for Preservice and Inservice Teachers. Reflective Practice, 3, 205-218.

Blackwell, A., Bowes, L., Harvey, L., Hesketh, A. J., \& Knight, P. T. (2001). Transforming Work Experience in Higher Education. British Educational Research Journal, 27, 269-285. 
Boud, D., Keogh, R., \& Walker, D. (1985). Reflection : turning experience into learning. London: Kogan Page.

Calderhead, J. (1988). Teachers' Professional Learning. London: Falmer.

Coffield, F. (2004). Learning styles and pedagogy in post-16 learning a systematic and critical review. London: Learning and Skills Research Centre.

Cox, E. (2005). Adult learners learning from experience: using a reflective practice model to support workbased learning. Reflective Practice, 6, 459-472.

Dewey, J. (1933). How we think : A restatement of the relation of reflective thinking to the educative process. Boston, Mass.: Heath.

Eraut, M., Alderton, J., Cole, G., \& Senker, P. (2000). Development of Knowledge and Skills at Work. In F. Coffield (Ed.), Differing Visions of a Learning Society : research findings. Volume 1 (pp. 231-262). Great Britain: Policy Press.

Griffin, M. L. (2003). Using Critical Incidents to Promote and Assess Reflective Thinking in Preservice Teachers. Reflective Practice, 4, 207-220.

Hatton, N., \& Smith, D. (1995). Reflection in teacher education: Towards definition and implementation. Teaching and Teacher Education, 11(1), 33-49.

Johns, C. (1994). Guided Reflection. In A. Palmer, S. Burns \& C. Bulman (Eds.), Reflective practice in nursing: the growth of the professional practitioner (pp. 110-130). Oxford: Blackwell Scientific Publications.

Kagan, J., Rosman, B., Day, D., Albert, J., \& Phillips, W. (1964). Information Processing and the Child (Vol. 78): Psychological Monographs, 78.

Kember, D., Jones, A., Loke, A., Mckay, J., Sinclair, K., Tse, H., et al. (1999). Determining the level of reflective thinking from students' written journals using a coding scheme based on the work of Mezirow. International Journal of Lifelong Education, 18(1), 18 - 30.

Kember, D., Leung, D. Y. P., Jones, A., Loke, A. Y., McKay, J., Sinclair, K., et al. (2000). Development of a Questionnaire to Measure the Level of Reflective Thinking. Assessment and Evaluation in Higher Education, 25(4), 381 - 395.

Kolb, D. A. (1984). Experiential Learning : experience as the source of learning and development. Upper Saddle River, NJ.: Prentice-Hall.

LaBoskey, V. K. (1993). A Conceptual Framework for Reflection in Preservice Teacher Education. In J. Calderhead \& P. Gates (Eds.), Conceptualizing Reflection in Teacher Development (pp. 23-38). London: Washington Falmer Press.

LaBoskey, V. K. (1994). Development of reflective practice : a study of preservice teachers. New York ; London: Teachers College Press.

Little, B. (2004). Employability and Work-based Learning. York: Higher Education Academy.

Maddocks, A., \& Wright, B. (2004). The RAPID Progress File: a tool to facilitate work placements in Built Environment disciplines [Electronic Version]. CEBE 
Transactions, 1, 39-47. Retrieved 6th April 2008 from

http://www.cebe.heacademy.ac.uk/transactions/pdf/MADDOCKSAlan.pdf.

Mezirow, J. (1990). Fostering critical reflection in adulthood : a guide to transformative and emancipatory learning. San Francisco: Jossey-Bass Publishers.

Moon, J. A. (1999). Reflection in Learning and Professional Development : theory and practice. London: Kogan Page.

Orland-Barak, L. (2005). Portfolios as Evidence of Reflective Practice: what remains 'untold'. Educational Research, 47(1), 25 - 44.

Platzer, H., Snelling, J., \& Blake, D. (1997). Promoting Reflective Practitioners in Nursing: a review of theoretical models and research into the use of diaries and journals to facilitate reflection. Teaching in Higher Education, 2(2), 103 121.

RIBA. (2008). Professional Education and Development Resource. Retrieved 1/04/2008, from www.pedr.co.uk

Riding, R. J., \& Rayner, S. (1998). Cognitive Styles and Learning Strategies. London: David Fulton.

Roberts, A., \& Findlay, H. (Awaiting Publication). Reflectors, Converts and the Dissengaged: A study of students perceptions of undertaking learning journals. Awaiting Publication.

Roberts, A., \& Mizban, N. (2008). E-Portfolios in the Workplace Project :analysis of student interview data. Cardiff: CEBE.

Samuels, M., \& Betts, J. (2007). Crossing the Threshold from Description to Deconstruction and Reconstruction: using self-assessment to deepen reflection. Reflective Practice, 8, 269-283.

Schön, D. A. (1983). The Reflective Practitioner : how professionals think in action. London: Temple Smith.

Smith, K., Clegg, S., Lawrence, E., \& Todd, M. J. (2007). The challenges of reflection: students learning from work placements. Innovations in Education and Teaching International, 44(2), 131 - 141.

Smith, K., \& Tillema, H. (2003). Clarifying Different Types of Portfolio Use. Assessment \& Evaluation in Higher Education, 28, 625-648.

Tripp, D. (1993). Critical incidents in teaching : developing professional judgement. London: Routledge.

Valli, L. (1993). Reflective Teacher Education Programmes: An Analysis of Case Studies. In J. Calderhead \& P. Gates (Eds.), Conceptualizing Reflection in Teacher Development (pp. 11-22). London: Washington Falmer Press.

Van-Manen, M. J. (1977). Linking Ways of Knowing with Ways of Being Practical. Curriculum Inquiry, 6(3), 205-228. 
Walker, D. (1985). Writing and Reflection. In D. Boud, R. Keogh \& D. Walker (Eds.), Reflection : turning experience into learning (pp. 52-68). London: Kogan Page.

Zeichner, K., \& Wray, S. (2001). The Teaching Portfolio in US Teacher Education Programs: what we know and what we need to know. Teaching and Teacher Education, 17(5), 613-621. 


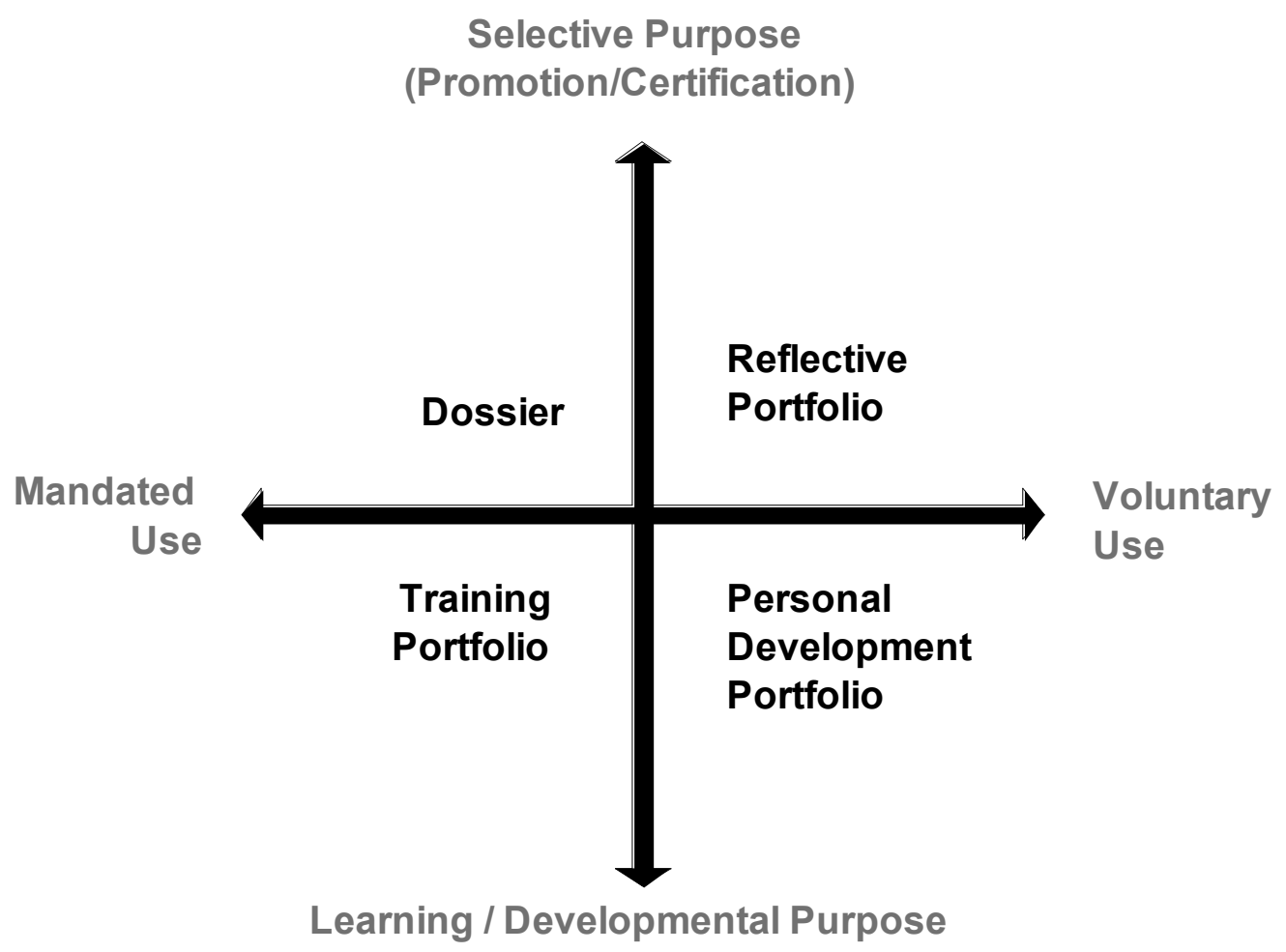

Figure 1. Smith and Tillema's model of portfolio use (K. Smith \& Tillema, 2003)

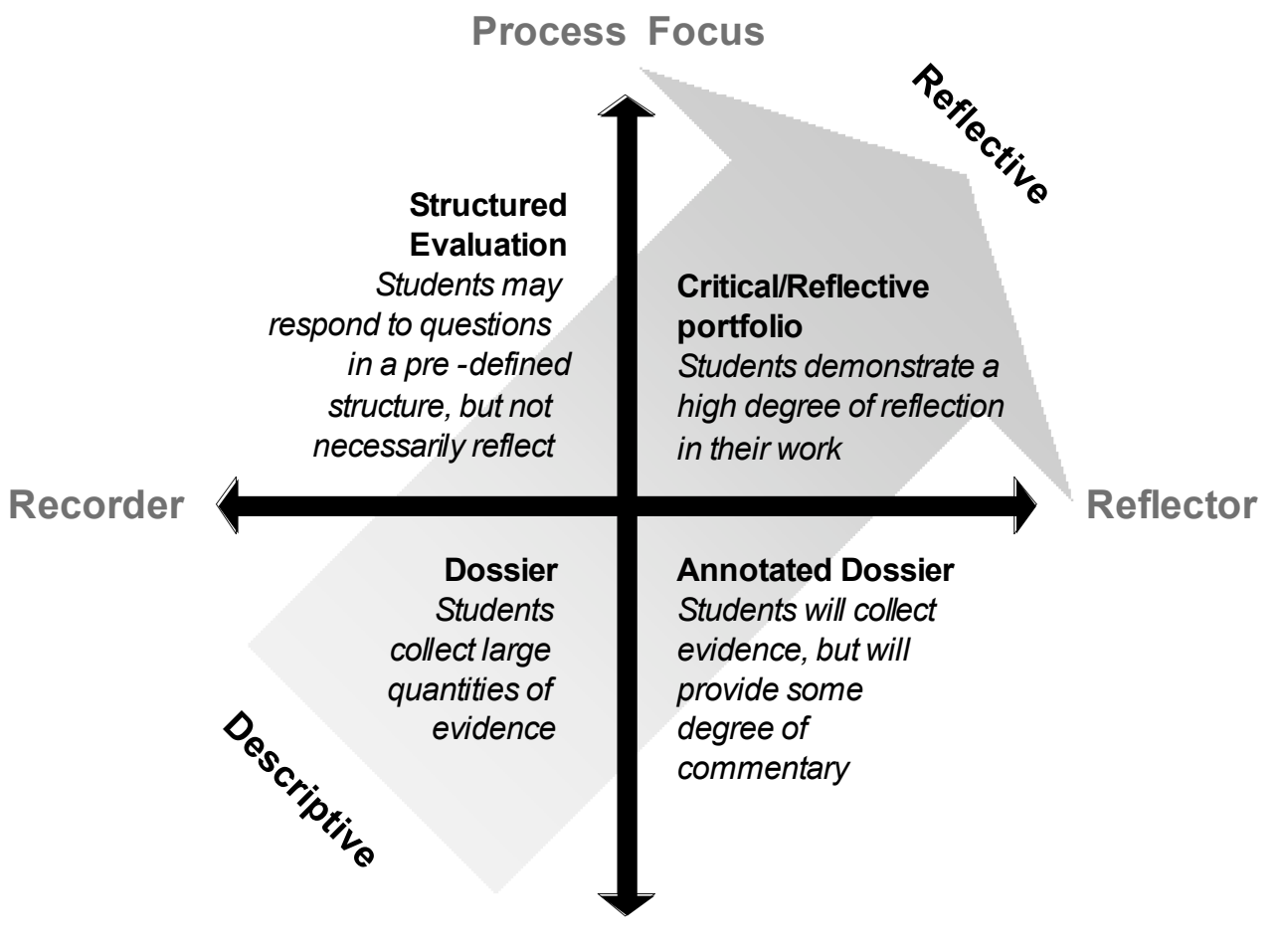

Product Focus

Figure 2 Proposed model connecting focus of reflection, propensity to reflect, and likely student output. 